\title{
Teachers' Perception of the Need for Functional Computer Laboratories in Secondary Schools in Nsukka Education Zone
}

\author{
Odo, Chinasa R. \\ Department of Computer Science, Enugu State College of Education (Technical), Enugu-Nigeria
}

Odo A. I.

Department of Computer Engineering, Enugu State University of Science and Technology, Enugu-Nigeria

\section{Doi:10.5901/jesr.2014.v4n7p115}

\begin{abstract}
This is a descriptive survey aimed to investigate teachers' perception of the need for functional computer science laboratories in secondary schools in Nsukka education zone. A sample of 150 teachers was drawn from a population of 1539 teachers in Nsukka education zone using multi stage sampling procedure. Three research questions and two hypotheses guided the study. Instrument for data collection was questionnaire; containing 17 items with 4 point scale of Strongly Agree, Agree, Disagree and Strongly Disagree. t-test and one way ANOVA statistics were used for data analysis. Results showed that teachers of secondary schools in Nsukka education zone agree that there is need for functional computer science laboratory. It also showed that teachers' perception of the need for functional computer science laboratory is not dependent on gender. Furthermore, educational status has no influence on teachers' perception on the need for functional computer science laboratories. The implication of the finding is that the present status of computer science laboratories cannot meet up with the global challenge of this technological age. It was recommended that government should provide basic infrastructure necessary for the acquisition of necessary skill development. Teachers should be sent for training in order to be current in teaching.
\end{abstract}

Keywords: Perception, Functional, Computer Laboratory, Teacher.

\section{Introduction}

The usage of computer technology as instructional material in teaching has indeed enhanced teaching and learning. Globally, computer has been adopted in every sphere of human endavour: business, agriculture, government and education. In line with the global adoption of computer, the federal government of Nigeria in 1987 introduced computer education in secondary schools. The general objectives of the policy of the National committee on computer 1988 include: To bring about a computer literate society in Nigeria by the mid-1990s. To enable the present school children to appreciate and use the computer in various aspects of life and in future employment.(Report on National Committee on Computer Education, 1988).

The above policy cannot materialize into a meaningful gain without a standard computer laboratory. Odo and Ugwu (2011) noted thatscience and technology education equip individuals with the requisite skills to transform the available resources into desired products for local use and for export. As a result, to build a strong computer science and technology innovation capacity, computer laboratories at the formative level should be made paramount.

A computer laboratory is a facility that provides controlled conditions in which computer research, experiments, and measurement can be performed. Computer laboratories are most essential and important in computer science since science cannot be taught effectively without testing, experimentation and demonstration of the scientific facts and computer science laboratories are the only means to accomplish that effectively. Meanwhile, in secondary schools, demonstration of practical work is the responsibility of a teacher. However, for computer science education to be successful in Nigeria, there is need for establishment of functional computer laboratory and training of teachers to enable them keep abreast with the insurgence technologies (Odo and Ugwu, 2011). This situation will enable the teacher regardless of the gender, and qualifications to successfully transfer the theoretical knowledge into skill application. It is therefore imperative that teachers whether male or female should posses the necessary capacity to utilize computer to teach in secondary schools. To teach in secondary school in Nigeria, teachers are required to have acquired a minimum of Nigeria Certificate on Education (NCE), B.Sc in Education or B.Ed or Masters degree or above. 
On the other hand, laboratory work is a responsibility of the students. It provides the students with requisite opportunities for the development of indispensable laboratory skills for learning how scientific knowledge and principles work in the practical situation. It enables them to know how facts are discovered in computer science. Therefore teachers of secondary school believe that provision of standard and functional computer laboratories will enable students to have the interest to harvest the unavoidable opportunity of skill acquisition because, students are required most times to do independent practical work in the laboratory.

However, teaching computer science without corresponding laboratory practical, due to inadequately prepared teachers and lack of basic infrastructure, will result in producing computer science graduates with trembling foundations and skills that are completely disconnected from industrial realities. The effect is that those graduates will be unable to make any meaningful contribution to economic development and technological breakthrough and this will perpetually keep Nigerians at the mercy of other nations for basic technological necessities.

Consequently, the world is becoming a web and the tool to get there is a well equipped computer laboratory with Desktop/laptop and reliable internet access. It is sad that Nigerian secondary school laboratories are seriously suffering neglect. Most of the schools do not even have a computer laboratory. The current situation of teaching and learning of computer education in Nigeria ranging from primary to university level is inability to prepare teachers, lack of basic infrastructure, neglect in maintenance of hardware and other peripherals and inability to maintain standard computer laboratories. This is due to high level of corruption which has stolen the conscience of Nigerian leaders. It is quite disheartening that during accreditation the National University Commission, National Commission for Colleges of Education or National Association of Principals of Secondary Schools will know that most of the equipments and human resources in the schools are borrowed in other to scale through accreditation, while they will transfer their children to overseas where there is functional education.

In this particular context, functional computer laboratory is a facility with clusters of computer with proper software and hardware resources where students will be getting hand on experience of the theoretical knowledge they have acquired, with a qualified teacher to take students on practical session.

\section{Purpose of the Study}

The major purpose of this study was to investigate the teachers' perception of the need for functional computer science laboratories among secondary school teachers in Nsukka education zone. Specifically, the study aim to determine;

1. Teachers' perception of the need for functional computer science laboratories in Nsukka education zone.

2. Teachers' perception of the need for functional computer laboratories in secondary school in Nsukka education zone based on gender.

3. Teachers' perception of the need for functional computer laboratories in secondary school in Nsukka education zone based on academic qualifications

\section{Research Questions}

The following research questions were raised to guide the study

1. What is teachers' perception of the need for functional computer laboratories in Nsukka education zone?

2. Is teachers' perception of the need for functional computer laboratory in secondary school in Nsukka education zone based on gender?

3. Is teachers' perception of the need for functional computer laboratory in secondary school in Nsukka education zone based on academic background?

\section{Hypothesis}

The following hypotheses were tested at 0.05 level of significance

Ho1: Gender will have no significant difference in the mean perception scores of teachers' regarding the need for functional computer laboratory in secondary schools in Nsukka education zone.

Ho2: Academic qualification will have no significant difference in the mean perception scores of teachers' perception of the need for functional computer laboratory in secondary schools in Nsukka education zone. 


\section{Research Methods}

The study adopted descriptive survey design. Population for the study comprised all the 1539 secondary school teachers in Nsukka education zone (PPSMB, 2010). Cluster sampling procedure was adopted. Each local government area was regarded as a cluster. Two schools from each of the three local government areas that make up the zone were drawn using balloting. Twenty five teachers were drawn from each of the six selected schools using the systematic random sampling technique. Through this procedure a sample of 150 teachers was drawn.

Instrument for data collection was an 17 item questionnaire made up of two sections, A \& B. the section A elicited information on the demographic variables of the teachers while, section B contained 15 item statements with a 4 option response scale of Strongly Agree (SA) Agree (A) Disagree (D), and Strongly Disagree (SD), with nominal values of 4, 3, 2 and 1 respectively.

The Section B contained statements that addressed the respective dimensions of functional computer laboratories. Validity of the instrument was established through the judgment of three experts in computer education. Reliability of the instrument was done using test re-test method. The second test was given after three days of the first one. Twenty copies of the instrument were administered on twenty teachers in Agbani education zone. The correlation coefficient of the two sets of scores yielded 0.83 using Cronbach Alpha statistic for test of internal consistency.

The research questions were answered using mean and standard deviation. The four response options of SA, A, D and SD were weighted 4, 3, 2 and 1 respectively, and coded to the Statistical Package Social Sciences (SPSS). A criterion mean of 2.50 was established. Mean responses of 2.5 and above were regarded as agreed while mean responses below 2.50 were regarded as disagree. The t-test and one way ANOVA statistics were employed in verifying the null hypotheses, at .05 level of significance.

\section{Research Procedure}

The instrument used for data collection was structured questionnaire named Teacher's Perception of the Need for Functional Computer Laboratory Questionnaire. (TPNFFCL). Two research personnel received training from the researchers on the administration and collection of the questionnaire. The questionnaires were administered to the respondent with the help of the trained researcher and were collected on the spot.

\section{Results}

Table 1: Mean Ratings on the Responses on the Teachers' Perception of the Need for Functional Computer Science Laboratories In Nsukka Education Zone. N = 150

\begin{tabular}{clrcc}
\hline S/N & Item Statement & Mean & SD & Remark \\
\hline 1 & Computer hardware equipments should be provided in the laboratory for teaching and learning. & 2.68 & 0.77 & Agreed \\
2 & Software resources should be made available in computer laboratories & 2.82 & 1.03 & Agreed \\
3 & Computer laboratory should be provided with alternative power source. & 2.57 & 0.98 & Agreed \\
4 & Computer laboratory should have internet access & 2.63 & 0.98 & Agreed \\
5 & Multimedia equipments should be provided. & 2.83 & 0.96 & Agreed \\
6 & Hearing aids should be provided for special students with disabilities & 2.71 & 1.01 & Agreed \\
7 & Computer science curriculum should be reviewed from time to time. & 2.63 & 0.85 & Agreed \\
8 & Teachers should be sent for workshop for training and re-training & 2.94 & 0.91 & Agreed \\
9 & Proper manpower should be employed from computer field of study to work as laboratory attendants & 2.89 & 1.03 & Agreed \\
10 & Computer research grant should be made available for the teachers. & 3.19 & 0.85 & Agreed \\
11 & National computer research center should be provided by the government to attract our foreign base & 2.79 & 0.82 & Agreed \\
& scientist home. & & & \\
12 & Conducive environment should be provided for the available equipments & 2.98 & 0.72 & Agreed \\
13 & Computer laboratory should be made accessible for both students and teachers. & 2.93 & 0.92 & Agreed \\
14 & There should be routine maintenance on computer equipments in the laboratory. & 2.77 & 0.93 & Agreed \\
15 & Only male teachers should be allowed to teach computer laboratory practicals & 1.79 & 0.69 & Disagreed \\
Grand mean & 2.74 & 0.90 & Agreed \\
\hline
\end{tabular}


Table 1 contains the result of the responses on the teachers' perception of the need for functional computer science laboratories in Nsukka education zone. The table shows that teachers agreed that there is need to have a functional computer laboratory in schools except item 15 which disagree that only male staff should be allowed to teach computer laboratory practical.

Table 2: Mean Responses on Teachers' Perception of the Need for Functional Computer Laboratory in Secondary School in Nsukka Education Zone is Based on Gender.

\begin{tabular}{|c|c|c|c|c|c|c|}
\hline \multicolumn{7}{|c|}{ Teachers $=150$} \\
\hline \multirow[t]{2}{*}{ Items } & \multicolumn{3}{|c|}{ Male $=89$} & \multicolumn{2}{|c|}{ Female $=61$} & \multirow[b]{2}{*}{ Remark } \\
\hline & Mean & SD & Remark & Mean & SD & \\
\hline 1 & 2.61 & 0.74 & Agreed & 2.77 & 0.80 & Agreed \\
\hline 2 & 2.52 & 1.02 & Agreed & 3.24 & 0.90 & Agreed \\
\hline 3 & 2.62 & 1.02 & Agreed & 2.47 & 0.92 & Disagreed \\
\hline 4 & 2.62 & 0.92 & Agreed & 2.63 & 1.08 & Agreed \\
\hline 5 & 2.58 & 0.91 & Agreed & 3.19 & 0.92 & Agreed \\
\hline 6 & 2.84 & 0.92 & Agreed & 2.50 & 1.10 & Agreed \\
\hline 7 & 2.46 & 0.89 & Disagreed & 2.86 & 0.74 & Agreed \\
\hline 8 & 2.98 & 0.84 & Agreed & 2.86 & 1.00 & Agreed \\
\hline 9 & 2.83 & 1.09 & Agreed & 2.98 & 0.92 & Agreed \\
\hline 10 & 3.10 & 0.92 & Agreed & 3.31 & 0.71 & Agreed \\
\hline 11 & 2.86 & 0.71 & Agreed & 2.68 & 0.95 & Agreed \\
\hline 12 & 3.08 & 0.82 & Agreed & 2.81 & 0.53 & Agreed \\
\hline 13 & 2.84 & 0.99 & Agreed & 3.06 & 0.79 & Agreed \\
\hline 14 & 2.73 & 1.00 & Agreed & 2.81 & 0.80 & Agreed \\
\hline 15 & 1.74 & 0.71 & Disagreed & 1.85 & 0.65 & Disagreed \\
\hline Grand mean & 2.69 & 0.90 & Agreed & 2.80 & 0.85 & Agreed \\
\hline
\end{tabular}

Table 2 only two items showed disagree for male that is item $7 \& 15$ and two items also showed disagree for female i.e. item $3 \& 15$. Therefore, with the grand mean of 2.69 and 2.80 both male and female teachers agreed that there is need for secondary school laboratory to be equipped with basic infrastructures to enable functional computer laboratory.

Table 3: Mean Responses on Teachers' Perception of the Need for Functional Computer Laboratory in Secondary School in Nsukka Education Zone Based by Academic Qualification.

\begin{tabular}{cccccccccc}
\hline Items & \multicolumn{3}{c}{ NCE $=\mathbf{4 7}$} & \multicolumn{3}{c}{ B.Sc $=\mathbf{4 0}$} & \multicolumn{2}{c}{ Master's and above $=\mathbf{6 3}$} \\
& Mean & SD & Remark & Mean & SD & Remark & Mean & SD & Remark \\
\hline 1 & 2.65 & 0.66 & Agreed & 2.67 & 0.76 & Agreed & 2.69 & 0.85 & Agreed \\
2 & 2.65 & 1.23 & Agreed & 2.75 & 0.86 & Agreed & 2.98 & 0.95 & Agreed \\
3 & 2.85 & 0.85 & Agreed & 2.25 & 0.89 & Disagreed & 2.55 & 1.07 & Agreed \\
4 & 2.72 & 0.92 & Agreed & 2.30 & 0.82 & Disagreed & 2.77 & 1.08 & Agreed \\
5 & 2.93 & 0.84 & Agreed & 2.57 & 1.03 & Agree & 2.92 & 0.98 & Agreed \\
6 & 2.72 & 0.99 & Agreed & 2.82 & 1.10 & Agreed & 2.61 & 0.97 & Agreed \\
7 & 2.65 & 0.84 & Agreed & 2.92 & 0.69 & Agreed & 2.41 & 0.90 & Disagreed \\
8 & 2.74 & 0.79 & Agreed & 3.25 & 0.70 & Agreed & 2.88 & 1.06 & Agreed \\
9 & 2.82 & 1.06 & Agreed & 3.00 & 1.03 & Agreed & 2.87 & 1.00 & Agreed \\
10 & 3.31 & 0.83 & Agreed & 3.22 & 0.83 & Agreed & 3.06 & 0.87 & Agreed \\
11 & 2.48 & 0.74 & Disagreed & 2.87 & 0.91 & Agreed & 2.96 & 0.76 & Agreed \\
12 & 2.97 & 0.53 & Agreed & 2.95 & 0.95 & Agreed & 3.00 & 0.69 & Agreed \\
13 & 3.08 & 0.74 & Agreed & 2.55 & 1.15 & Agreed & 3.06 & 0.82 & Agreed \\
14 & 2.80 & 0.99 & Agreed & 2.50 & 0.90 & Agreed & 2.90 & 0.87 & Agree \\
15 & 1.89 & 0.69 & Disagree & 1.60 & 0.63 & Disagreed & 1.82 & 0.70 & Disagree \\
Grand mean & $\mathbf{2 . 7 5}$ & $\mathbf{0 . 8 4}$ & Agreed & $\mathbf{2 . 6 8}$ & $\mathbf{0 . 8 8}$ & Agreed & $\mathbf{2 . 7 7}$ & $\mathbf{0 . 9 1}$ & Agreed \\
\hline
\end{tabular}

Table 3 show teachers' response on whether teachers' perception of the need for functional computer laboratory in secondary school in Nsukka education zone based on academic background. From the table above, only items 11 \& 15 has disagreement for HND, items 2, 4 and 15 showed disagreement for B.Sc and items 7 \& 15 also showed disagree for 
Masters. In general, with the grand mean of 2.75, 2.68 and 2.77 for NCE, B.Sc and Masters and above shows that teachers with different qualifications have adequate perception on the need for functional computer laboratory.

Table 4: Summary of the t-test Statistics Verifying the Difference Between Male and Female Teachers Regarding their Perception on the Need for Functional Computer Laboratory In Secondary Schools in Nsukka Education Zone.

\begin{tabular}{ccccccccc}
\hline Gender & N & Mean & SD & df & t-cal & t-tab & P & Decision \\
\hline Male & 89 & 2.69 & 0.90 & & & & & \\
\hline Female & 61 & 2.80 & 0.85 & & & & & \\
\hline
\end{tabular}

In table 4 the mean ratings of male and female teachers have been compared using the t-test statistics. The data show that t-cal $(-0.71)<\mathrm{t}$-critical table value (1.96). This shows that gender do not have any influence on teachers' perception on the need for functional computer laboratory in secondary schools in Nsukka Education Zone and therefore the $\mathrm{Ho}_{1}$ is accepted at .05 level of significance.

Table 5: Summary of the ANOVA Statistic Verifying the Teachers' Perception on the Need for Functional Computer Laboratory in Secondary Schools in Nsukka Education Zone is Based on the Educational Qualifications.

\begin{tabular}{|c|c|c|c|c|c|c|c|}
\hline Source & Df & Sum of squares & Mean square & f-cal & f-tab & $\mathbf{P}$ & Decision \\
\hline Between Group & 2 & 14.53 & 7.26 & & & & \\
\hline Within Group & 147 & 75.93 & 0.51 & & & & \\
\hline
\end{tabular}

In table 5, one way ANOVA was applied in analyzing $\mathrm{Ho}_{2}$. The data as contained in Table 5 show that $\mathrm{f}$-cal $(2.39)<\mathrm{f}$-tab (3.18) at .05 level of significance, therefore, the $\mathrm{Ho}_{2}$ is upheld. Teachers' perception on the need for functional computer laboratory in secondary schools in Nsukka Education Zone is not dependent on their academic background.

\section{Summary of findings}

1. Teachers of secondary schools in Nsukka Education Zone believe that there is need for functional computer laboratories with basic ICT infrastructures. This is to enable the teachers impact the necessary practical knowledge on students.

2. Teachers of secondary schools in Nsukka Education Zone agreed that software and hardware facilities should be provided with internet access for research development.

3. Teachers of secondary schools in Nsukka Education Zone also believed that teachers should be sent for training and re-training to enable them to understand how to use the ever emerging technology in teaching. This is because, as a leader in teaching their subject, they should be aware of the current educational trend.

4. Teachers of secondary schools in Nsukka Education Zone believed that computer science syllabus should be reviewed from time to time.

\section{Discussions}

The study generated information on teachers' perception of the need for functional computer laboratory in secondary schools in Nsukka Education Zone. The finding pertaining to research question 1 revealed that teachers' perception of the need for functional computer laboratory in secondary schools in Nsukka Education Zone is adequate. This finding is not unanticipated considering the educational background of the people under study. This is because they understand that government has not provided an enabling environment by prioritizing science and technology education through the provision of functional computer laboratories that encourages and motivates researchers and students through effective coordination. This is in line with Oduyaiye (2007) who stated that a major setback to the implementation of the computer policy is the inadequate supply or provision of computer facilities which is required to make the policy successful.

This is in agreement with the statement of Okah, (2010) who stated that a functional and well-equipped national laboratory serves as a brainstorming and research hub for scientists and engineers as well as a training center for upcoming scientists. Therefore, governments should be responsible for providing adequate infrastructures for schools.

The finding pertaining to research question 2 on whether teachers' perception of the need for functional computer laboratory in secondary school in Nsukka education zone is influenced by gender revealed that gender does not have 
any influence on the teachers' response. This finding is in agreement with the finding of Durosaro, (2006), who stated that for our future teachers to operate effectively and efficiently, regardless of their gender, they must imbibe new technologies and methodologies of the advanced countries of the world.

The finding pertaining to research question 3 on whether teachers' perception of the need for functional computer laboratory in secondary school in Nsukka education zone is determined by academic qualifications indicates that the response of teachers is not determined by academic qualification. The finding is in line with the observation of (Riel, 1998) who noted that teachers need to be more skilled in academics in order to direct students properly through the huge quantities of rich information in the globe. The present finding is also in agreement with (Haddad, 2007) who noted that the quality of education is dependent on the development of high quality teachers and a high quality teacher is due to his/her academic qualifications.

The finding pertaining to hypothesis one $\left(\mathrm{HO}_{1}\right)$ revealed that teachers' perception on the need for functional computer laboratory in secondary schools in Nsukka Education Zone is not affected by gender. The finding pertaining to hypothesis one $\left(\mathrm{HO}_{2}\right)$ revealed that on teachers' perception on the need for functional computer laboratory in secondary schools in Nsukka Education Zone is not dependent of their academic qualifications.

\section{Implications of the Study}

Due to technological revolutions, Nigeria is facing the danger of lack of technological know-how due to non functional computer laboratory. This situation makes Nigerians to remain primitive and vulnerable due to lack of technological base necessary for robust and sustainable economic prosperity. Nigerians cannot be accorded its due respect as long as it continues to take a back seat in science and technology. Nigerians will continue to remain at the mercy of foreign countries for technological development if nothing is done to change the situation. The un-forgiving consequence is unemployment and crime currently ravaging the length and breadth of the Nation.

\section{Recommendations}

Government should own up to the responsibility of providing basic infrastructures necessary for acquisition of computer skills, which should include the provision of functional laboratories. The government should also put in place science and technology policies to drive the established system and also provide the requisite infrastructures and conducive laboratory environment, not only for reduction of brain-drain, but also to serve as a necessary vehicle for luring foreignbased Nigerian scientists and engineers back home.

The ministry of education should try and send teachers for training from time to time in order to meet up with the technological challenges.

Teachers should also see the acquisition of the computer laboratory skill as a necessity and make crucial move towards learning the new skills in computer technology so that they will be able to compete with their colleague in other parts of the world.

\section{References}

Durosaro, D. O. (2006). Teacher education in Nigeria: past, present and future challenges. The Pacesetter Journal, 13(1), Pp43-53 FRN (1987).National Policy of Education. Abuja, Federal Government Printers.

FRN (1988).National Computer Policy.Abuja, Federal Government Printers,

Haddad, W.D. 2001. Technology and Teacher Education: Making the Connection.Editorial Technologia.Oakton: Academy for Educational Development

Post Primary School Management Board (2010).Nominal role of Teachers in Enugu State.

Riel, M. M. (1998). Just-in-time learning or learning communities. Paper presented at the Fourth Annual Conference of the Emirates Center for Strategic Studies and Research held at Abu Dhabi.

Odo A. I and Ugwu R. C., (2010). Scienc and Technological Education: Strategic tool for National Development in Nigeria. Journal of Nigerian Educational Research Association 15 (1) Pp 132-136

Oduwaiye R.O (2007) Teachers Competency and Availability of Facilities as Correlates of Effective Computer Education in Selected Secondary Schools in Kwara State The Nigerian Journal of Educational Administration and Planning 7 (1) Pp191 - 199

Okah, E. (2010). Tragedy of Nigeria's education system Retrieved May 122012 form http://www.nigeriabestforum.com/blog 